\title{
Comparison of long-term clinical outcome between patients with chronic versus acute type $B$ aortic dissection treated by implantation of a stent graft: a single-center report
}

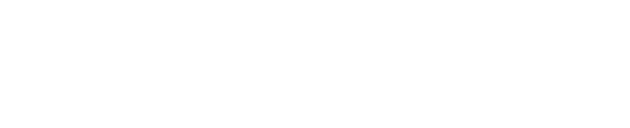

\section{Shao-Liang Chen \\ Jian-Cheng Zhu \\ Xiao-Bo Li \\ Fei Ye \\ Jun-Jie Zhang \\ Zhi-Zhong Liu \\ Nai-Liang Tian \\ Song Lin \\ Cheng-Yu Lv}

Nanjing First Hospital, Nanjing Medical University, Nanjing, People's Republic of China
Correspondence: Shao-Liang Chen Nanjing First Hospital, Nanjing Medical University, 210006 Nanjing, People's Republic of China

Tel +8625 52208048

Fax +86 2552208048

Email chmengx@।26.com
Background: Stent grafting for treatment of type B aortic dissection has been extensively used. However, the difference in the long-term clinical outcome between patients with chronic versus acute type B aortic dissection remains unknown. This study aimed to analyze the difference in long-term clinical outcome after endovascular repair for patients with chronic ( $\geq 2$ weeks) versus acute ( $<2$ weeks) type B aortic dissection.

Methods: Between May 2000 and June 2011, a total of 174 patients with type B aortic dissection (56 chronic, 118 acute) treated by endovascular repair were studied prospectively. Follow-up three-dimensional computed tomography scanning and aortoangiography were scheduled at 3-6 months after the index procedure. Propensity score matching was used to compare the difference in the endpoint between the two groups.

Results: The procedure-related event rate was $18.6 \%$ in the acute group and $5.4 \%$ in the chronic group $(P=0.021)$, but this difference became nonsignificant after propensity score matching. At the end of follow-up (mean 2.49 years), overall and aorta-related mortality was $11.0 \%$ and $7.6 \%$, respectively, in the acute group, and was not significantly different from that in the chronic group (3.6\% and 3.6\%, $P=0.148$ and $P=0.506$, respectively). Both false and true lumina showed significant remodeling over time, with $>93 \%$ complete false-lumen thrombosis. Untreated tear and type I endoleak were predictors of clinical events during follow-up.

Conclusion: Comparable long-term clinical results were achieved in patients with chronic or acute type B aortic dissection after implantation of a stent graft.

Keywords: aortic dissection, endovascular repair, procedure-related events, propensity score matching

\section{Introduction}

Formation of an intimal aortic tear, resulting from uncontrolled hypertension, pregnancy, trauma, bicuspid aortic valve, Marfan syndrome, Ehlers-Danlos syndrome, Turner syndrome, syphilis, cocaine use, or surgical procedures (including aortic or mitral valve repair, coronary artery bypass grafting, cardiac catheterization) allows blood to split the aortic wall into a false and a true lumen. ${ }^{1}$ Patients may be pain-free if the false lumen is connected with the true lumen at the distal portion of the descending aorta. ${ }^{2}$ However, several features put patients at high risk, ${ }^{3,4}$ ie, progressive enlargement of the false lumen, remote organ or peripheral artery malperfusion, occlusion of the subclavian or carotid arteries, and compromise of the ostial coronary artery by the false lumen. 
Classification of aortic dissection is mainly based on the initial site of the tears, ${ }^{5}$ with type A defined as tears at the ascending artery and type $\mathrm{B}$ as tears at the descending artery. In some cases, type B dissection can tear up to the aortic arch and lead to a more complex pattern of dissection. ${ }^{6}$ Although surgical replacement of the aorta is the standard of care for type A dissection, ${ }^{7}$ it is associated with increased mortality in type $\mathrm{B}$ dissection. With the development of novel endovascular devices, implantation of a stent graft has been found to produce results comparable with those of surgical procedures. ${ }^{8,9}$ Previous study with a small patient size reported an increased event rate if endovascular repair was performed at the acute stage. ${ }^{10}$ As a result, the current study aimed to compare the long-term clinical outcome for patients at the acute versus chronic stage of aortic dissection treated by endovascular repair before and after propensity score matching.

\section{Materials and methods Patient population}

Between May 2000 and June 2011, 321 patients with aortic dissection were studied prospectively. Of these patients, 10 died soon after admission, 27 (20 type A, seven type B) underwent surgery, and 110 with type B dissection (48 acute, 62 chronic) were put on maximal medication because they were clinically stable. Finally, 174 patients with type B dissection were transferred to Nanjing First Hospital and treated by implantation of a stent graft, and formed the basis of the present study (Figure 1). Our institutional review board approved this study, and full informed consent was obtained from each patient.

\section{Inclusion and exclusion criteria}

Inclusion criteria were type B aortic dissection (descending thoracic aorta $\geq 40 \mathrm{~mm}$ in diameter at onset of aortic dissection) with complications requiring surgical intervention, including visceral or leg ischemia, aortic rupture, refractory hypertension, refractory pain, or growth of ulcer-like projections.

Exclusion criteria were as follows: distance between the entry tear and left subclavian artery $<5 \mathrm{~mm}$; abdominal approach not feasible when diameter of the access artery (ie, the femoral and iliac artery) $<7 \mathrm{~mm}$; and existence of complications requiring emergency surgery, including cardiac tamponade, ischemia of the coronary artery or cervical branches, or aortic regurgitation.

\section{Interventional procedure}

Computed tomography (CT) and calibrated coronary and aortoangiography were performed preoperatively in

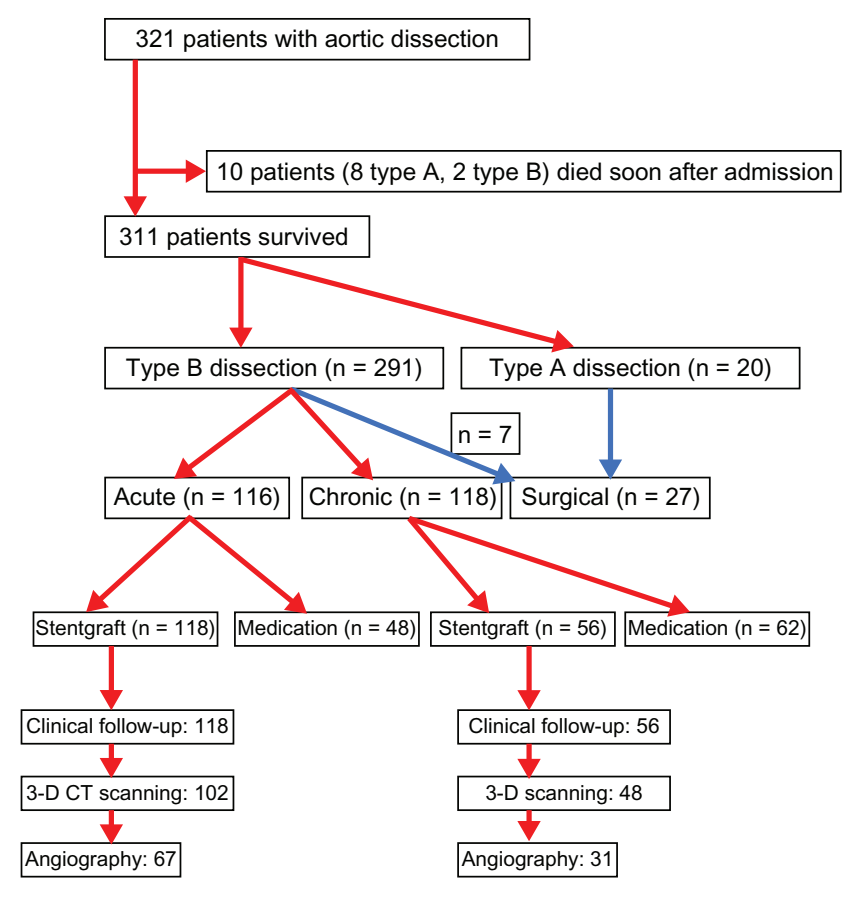

Figure I Study flow chart.

all patients. In patients with chronic dissection, the diameters of the stent grafts were determined to be approximately $10 \%$ larger than that of the aorta proximal to the entry tear, as measured on contrast-enhanced CT. In patients with acute dissection, approximately the same diameter as that of the aorta proximal to the entry tear was adopted as the diameter of the stent graft. The distance between the entry tear and the left subclavian artery was measured on a calibrated angiographic scan in all cases. Three-dimensional reconstruction or multiplanar reconstruction images elaborated from axial CT images were used in some cases to measure the length and shape of the entry tear. The length of the stent graft was $7.0 \mathrm{~cm}$ in most cases, in which the entry tear was like a pinhole. However, in some cases, the length of the stent graft was 10-12 cm or longer because the entry tear had a considerable longitudinal length. Percutaneous coronary intervention using a drug-eluting stent was performed just before the stent graft procedure if any epicardial coronary artery had a diameter stenosis $\geq 90 \%$ on visual estimation.

Individually selected stent grafts (Talent ${ }^{\mathrm{TM}}$, Medtronic Inc, Santa Rosa, CA; Willis ${ }^{\mathrm{TM}}$, Microport, Shanghai, People's Republic of China) were used to scaffold up to $20 \mathrm{~cm}$ of dissected thoracic aorta. The procedure was performed using digital angiography. The femoral artery could usually accommodate the 24 French stent-graft system, which was advanced over a stiff $260 \mathrm{~cm}$ wire navigated in the true lumen and deployed under rapid pacing ${ }^{11,12}$ or intravenous 
injection of a vasodilator drug. ${ }^{13}$ Intentional coverage of the left subclavian artery was accepted to avoid endoleak. ${ }^{14}$ Surgical revascularization of the left subclavian artery was performed at the discretion of the operator based on whether or not the patient developed symptoms related to coverage, ie, ischemia of the arm, brain, or spinal cord. In the presence of arteria lusoria, an incomplete circle of Willis, or a dominant left vertebral artery, a left subclavian artery bypass was placed before stenting. ${ }^{11,14,15}$ For patients having multiple tears, complete repair of the dissection was encouraged, with additional stents in branch vessels or use of a large bare metal stent in the aorta. Spinal drainage was performed if patients developed symptoms.

\section{Follow-up}

Clinical follow-up was performed by visit or telephone contact at one, 3, and 12 months within the first year after the index procedure, and yearly thereafter. Adverse events were monitored throughout the entire study period. Follow-up three-dimensional CT scanning was scheduled at one, 3 and 6 months after the index procedure unless clinical reasons indicated earlier. Surveillance aortoangiography was scheduled at 6 months after the stenting procedure. Clinical outcome and events were classified in accordance with reporting standards of the Ad Hoc Committee for Standardized Reporting Practices in Vascular Surgery/ International Society for Cardiovascular Surgery. ${ }^{1,16}$
An outcomes adjudication committee consisting of a cardiac surgeon, a vascular surgeon, and two cardiac interventionalists assessed each complication independently in a blinded fashion, with potential disagreements to be resolved by consensus. With serial tomographic imaging, all patients underwent evaluation for false lumen thrombosis and true lumen dimensions at the level of the dissected aorta.

\section{Definitions}

Dissection was considered an acute event if it occurred $<2$ weeks from onset of symptoms, and was considered chronic when occurring beyond 2 weeks. Complications were classified as access complications (requiring surgical revision, renal failure), procedure-related complications (retrograde dissection, organ or peripheral artery malperfusion, dissection rupture, type I endoleak, and stroke because of subclavian artery occlusion), and nonprocedure-related complications (including myocardial infarction, cancer, and multiple organ failure, or stroke with no relationship to stent grafting). Procedural success was defined as technically successful deployment of the endoprosthesis at the intended target location. Any death that occurred suddenly or could not be related to other causes was classified as being caused by aortic rupture. Reintervention was defined as the need for any surgical conversion or additional endovascular stent graft procedures.

Table I Baseline clinical characteristics

\begin{tabular}{|c|c|c|c|}
\hline & Chronic $(n=56)$ & Acute $(n=118)$ & $P$ \\
\hline Age, years & $53.96 \pm 10.69$ & $57.39 \pm 11.15$ & 0.052 \\
\hline Male, n (\%) & $44(78.6)$ & III (94.I) & 0.004 \\
\hline Hypertension, n (\%) & $49(87.5)$ & $102(86.4)$ & 1.000 \\
\hline On medication & $8(14.3)$ & $15(12.7)$ & 0.151 \\
\hline With positive family history & $3(5.4)$ & $9(7.6)$ & 0.671 \\
\hline Coronary artery disease, $\mathrm{n}(\%)$ & $18(32.1)$ & $30(25.4)$ & 0.369 \\
\hline Diabetes, $\mathrm{n}(\%)$ & $6(10.7)$ & $4(3.4)$ & 0.078 \\
\hline Hyperlipidemia, n (\%) & $2(3.6)$ & $13(11.0)$ & 0.148 \\
\hline Abuse of alcohol, n (\%) & $10(17.9)$ & $40(33.9)$ & 0.032 \\
\hline Current smoking, n (\%) & $38(67.9)$ & $71(60.0)$ & 0.402 \\
\hline COPD, n (\%) & $2(3.6)$ & $3(2.5)$ & 0.657 \\
\hline Previous stroke, $n(\%)$ & $4(7.1)$ & $5(4.2)$ & 0.713 \\
\hline Previous renal dysfunction, $\mathrm{n}(\%)$ & $3(5.4)$ & $5(4.2)$ & $0.47 \mid$ \\
\hline Complications at admission, $\mathrm{n}(\%)$ & $9(16.1)$ & $25(21.2)$ & 0.540 \\
\hline Congestive heart failure & $\mathrm{I}(\mathrm{l} .8)$ & $2(1.7)$ & 1.000 \\
\hline Pericardial effusion & $2(3.6)$ & $2(1.7)$ & 0.595 \\
\hline Acute myocardial infarction & 0 & 0 & NS \\
\hline Pleural effusion & $5(5.4)$ & $3(2.5)$ & 0.388 \\
\hline Non-pulsation at limbs & 0 & $9(7.6)$ & 0.059 \\
\hline $\begin{array}{l}\text { Time from onset of } \\
\text { symptom to admission, } \mathrm{h}\end{array}$ & $1608 \pm 957$ & $34 \pm 14$ & 0.001 \\
\hline
\end{tabular}

Abbreviation: COPD, chronic obstructive pulmonary disease. 


\section{Statistical analysis}

For continuous variables, binary distribution was tested and differences were evaluated using the independent twosamples $t$-test (if binary distribution) or the Mann-Whitney $U$ test (if nonbinary distribution). Categorical variables were compared using the Fisher's Exact test or $\chi^{2}$ test. KaplanMeier curves for event-free survival rate were generated and compared using the log-rank test. All tests were two-tailed. $P<0.05$ was considered to be statistically significant. The data were processed using the Statistical Package for the Social Sciences software package version 17.0 (SPSS, Inc, Chicago, IL, USA).

Propensity score matching was performed to avoid treatment selection bias and potential confounding factors, and to adjust for any significant differences in patient or lesion characteristics. The following variables were selected to calculate the propensity score by binary logistic regression: age, gender, height, weight, hypertension, diabetes, hyperlipidemia, serum creatinine, history of renal dysfunction, alcohol abuse, current smoking, chronic obstructive pulmonary disease, previous stroke, complications at admission (including congestive heart failure, pericardial effusion, acute myocardial infarction, pleural effusion, nonpulsation in peripheral arterial disease), coronary artery diameter stenosis $\geq 90 \%$, distance of tears to the left subclavian artery, stent number, stent diameter, stent length, left subclavian artery involved, additional tears and their location, and peripheral artery or remote organ malperfusion.
The discrimination and calibration ability of each propensity score model was assessed using the HosmerLemeshow statistic and the area under the receiver operator characteristic curve (procedure-related complication as the state variable, propensity score as the tested variable). The goodness-of-fit statistic was $4.866(P=0.772)$ and the area under the receiver operator characteristic curve for the model was 0.677 (ie, the c statistic). The new propensity score was then incorporated to assess the efficacy of stent grafting for the chronic versus acute groups. Hierarchical cluster analysis was used for development of a propensity score, matching pairs with a 1:1 match (nearest neighbor). Patients who did not have pairs were excluded from the final matched population.

\section{Results}

Of the 174 patients, 118 were assigned as acute ( $<2$ weeks) and 56 were assigned as chronic ( $\geq 2$ weeks), according to time from symptom onset (Table 1). All patients in the chronic group had tightly controlled hypertension and were pain-free. Baseline characteristics were comparable between the acute and chronic groups, except for the proportion of males $(94.1 \%$ versus $78.6 \%$, respectively, $P=0.004)$ and alcohol abuse $(33.9 \%$ versus $17.9 \%, P=0.032)$.

Most patients had a single dissection, but patients in the acute group had more multiple tears $(24.6 \%$ versus $7.1 \%$, Table 2). Most second tears were localized at the renal artery area, and complete repair was achieved in only one patient.

Table 2 Lesions and procedural characteristics

\begin{tabular}{|c|c|c|c|}
\hline & Chronic $(n=56)$ & Acute $(n=118)$ & $\mathbf{P}$ \\
\hline No dissections & & & 0.007 \\
\hline Single & $52(92.9)$ & $89(75.4)$ & \\
\hline Additional & $4(7.1)$ & $29(24.6)$ & \\
\hline Localized at the renal artery area & $4(100)$ & $29(100.0)$ & \\
\hline Simultaneously repair & 0 & I (3.6) & \\
\hline Distance of dissection to LSCA, cm & $2.49 \pm 2.09$ & $2.23 \pm 1.36$ & 0.387 \\
\hline Diameter of false lumen, $\mathrm{mm}$ & $38.67 \pm 5.69$ & $26.83 \pm 4.77$ & 0.001 \\
\hline $\begin{array}{l}\text { Time from onset of } \\
\text { symptom to procedure, } d\end{array}$ & $23.29 \pm 6.21$ & $4.83 \pm 3.65$ & $<0.001$ \\
\hline Stent number, $\mathrm{n}$ & $1.13 \pm 0.20$ & $1.76 \pm 0.87$ & 0.103 \\
\hline Stent diameter, $\mathrm{mm}$ & $36.45 \pm 4.34$ & $36.64 \pm 2.68$ & 0.725 \\
\hline Stent length, $\mathrm{mm}$ & $130.84 \pm 40.59$ & $136.11 \pm 40.83$ & 0.427 \\
\hline Coronary angiography, n (\%) & $38(67.86)$ & $84(71.19)$ & 0.257 \\
\hline I-vessel disease & $6(10.8)$ & $20(16.9)$ & 0.203 \\
\hline LAD lesion & $3(5.4)$ & $20(16.9)$ & 0.046 \\
\hline Multivessel disease & 0 & $8(6.8)$ & 0.088 \\
\hline $\mathrm{PCl}$ at same stage, $\mathrm{n}(\%)$ & $3(5.4)$ & $8(6.8)$ & 1.000 \\
\hline Renal artery occlusion, $\mathrm{n}(\%)$ & $4(7.1)$ & II (9.3) & 0.777 \\
\hline Iliac/femoral artery occlusion, $\mathrm{n}$ (\%) & 0 & $9(7.6)$ & 0.059 \\
\hline LSCA occlusion, $n(\%)$ & $3(5.4)$ & $8(6.8)$ & 1.000 \\
\hline
\end{tabular}

Abbreviations: LSCA, left subclavian artery; LAD, left anterior descending artery; PCl, percutaneous coronary intervention. 
Table 3 Comparison of clinical results for the acute versus chronic type B aortic dissection groups

\begin{tabular}{|c|c|c|c|}
\hline & Chronic $(n=56)$ & Acute $(n=118)$ & $P$ value \\
\hline Follow-up duration, years & $3.13 \pm 2.39$ & $2.76 \pm 2.39$ & 0.478 \\
\hline Procedural success, n (\%) & $56(100.00)$ & I I8 (I00.00) & 1.000 \\
\hline \multicolumn{4}{|l|}{ Intraprocedure, n (\%) } \\
\hline Aortic rupture & 0 & $\mathrm{I}(0.8)$ & 1.000 \\
\hline Needing surgical operation & 0 & 0 & NS \\
\hline Inhospital overall events, n (\%) & $6(10.7)$ & $28(23.7)$ & 0.064 \\
\hline Overall death & 0 & $9(7.6)$ & 0.059 \\
\hline Procedure-related events, n (\%) & $3(5.4)$ & $22(18.6)$ & 0.021 \\
\hline Reverse dissection & $\mathrm{I}(\mathrm{I} .8)$ & $\mathrm{I}(0.8)$ & 0.541 \\
\hline Organ or peripheral artery malperfusion & $2(3.6)$ & $13(11.0)$ & 0.148 \\
\hline Dissection rupture & 0 & $\mathrm{I}(0.8)$ & 1.000 \\
\hline Type I leakage & $\mathrm{I}(\mathrm{l} .8)$ & $14(11.9)$ & 0.039 \\
\hline LSCA occlusion leading to stroke & 0 & $2(1.7)$ & 1.000 \\
\hline Nonprocedure-related events, n (\%) & $3(5.4)$ & $12(10.2)$ & 0.392 \\
\hline Acute myocardial infarction & 0 & I $(0.8)$ & 1.000 \\
\hline Cancer & 0 & 0 & NS \\
\hline Multiorgan failure & 0 & $3(2.5)$ & 0.552 \\
\hline Non-LSCA occlusion leading to stroke & $3(5.4)$ & $7(5.9)$ & 1.000 \\
\hline Surgical operation for access site, $\mathrm{n}(\%)$ & I (I.8) & $3(2.5)$ & 1.000 \\
\hline Renal failure, n (\%) & $4(7.1)$ & $18(15.3)$ & 0.151 \\
\hline Without needing dialysis & $3(5.4)$ & II (9.3) & 0.553 \\
\hline Needing CRRT & $\mathrm{I}(\mathrm{I} .8)$ & $7(5.9)$ & 0.439 \\
\hline Reversible central complications, n (\%) & I (I.8) & $10(8.5)$ & 0.107 \\
\hline Overall stroke, n (\%) & $3(5.4)$ & $9(7.6)$ & 0.754 \\
\hline Paraplegia, n (\%) & 0 & 0 & NS \\
\hline Deep vein thrombosis, $\mathrm{n}(\%)$ & $\mathrm{I}(\mathrm{I} .8)$ & 0 & 0.322 \\
\hline Bleeding, n (\%) & $2(3.6)$ & $14(11.9)$ & 0.095 \\
\hline Needing transfusion & $\mathrm{I}(\mathrm{I} .8)$ & $10(8.5)$ & 0.107 \\
\hline Fever, n (\%) & $17(30.4)$ & $32(27.1)$ & 0.719 \\
\hline Death by end of follow-up, $n$ (\%) & $2(3.6)$ & $13(11.0)$ & 0.148 \\
\hline Aortic-related death & $2(3.6)$ & $9(7.6)$ & 0.506 \\
\hline \multicolumn{4}{|l|}{ Change in diameter of true lumen, $\mathrm{mm}$} \\
\hline Prior & $16.35 \pm 10.26$ & $18.32 \pm 15.79$ & 0.726 \\
\hline Post & $24.70 \pm 4.55$ & $25.02 \pm 4.78$ & 0.805 \\
\hline I month & $26.88 \pm 5.21$ & $27.20 \pm 5.42$ & 0.819 \\
\hline 3 months & $27.34 \pm 4.09$ & $27.48 \pm 6.05$ & 0.867 \\
\hline 6 months & $28.66 \pm 5.67$ & $28.97 \pm 5.73$ & 0.902 \\
\hline \multicolumn{4}{|l|}{ Diameter of false lumen at stented segment, $\mathrm{mm}$} \\
\hline Post & $20.11 \pm 7.35$ & $17.65 \pm 7.08$ & 0.702 \\
\hline I month & $18.68 \pm 5.43$ & $13.48 \pm 4.35$ & 0.430 \\
\hline 3 months & $17.35 \pm 14.65$ & $12.07 \pm 10.77$ & 0.047 \\
\hline 6 months & $15.02 \pm 15.63$ & $12.37 \pm 13.24$ & 0.582 \\
\hline Complete thrombosis, $\mathrm{n}(\%)$ & $53(94.6)$ & $108(91.5)$ & 0.707 \\
\hline
\end{tabular}

Abbreviations: LSCA, left subclavian artery; CRRT, continuous renal replacement therapy.

Medication did not limit progression of the false lumen in the chronic group $(48.67 \pm 5.69 \mathrm{~mm}$ versus $36.83 \pm 4.77$, $P=0.001)$. There were significant differences in stent number and length between the two groups. Coronary angiography was performed at the same stage in nearly $70 \%$ of patients and single-vessel disease was seen in $13 \%$ of patients, with the left anterior descending artery more often involved in the acute group $(16.9 \%$ versus $5.4 \%, P=0.046)$. Approximately $20 \%$ of patients had occluded peripheral arteries, with no significant difference between the groups.
Interventional procedures were successful in all patients (Table 3). There was one death due to aortic rupture immediately after the stiff wire was positioned in the ascending artery in the acute group. Overall inhospital events and mortality in the acute group were $23.7 \%$ and $7.6 \%$, respectively, and were not significantly different from those in the chronic group. Patients in the acute group had a significantly higher rate of procedurerelated events (18.6\%), than patients in the chronic group (5.4\%, $P=0.021)$, but the incidence of individual point 


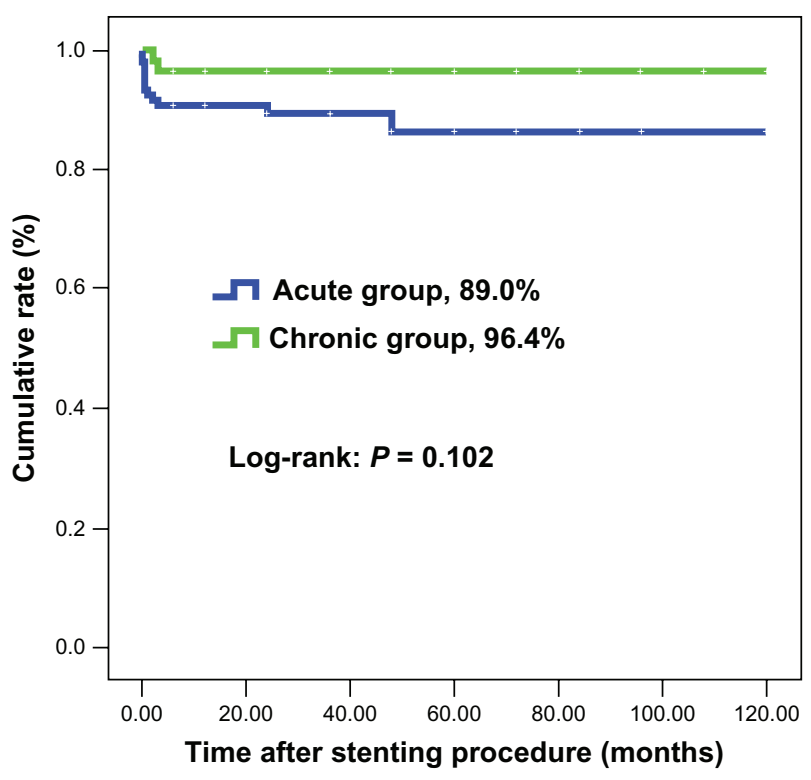

Figure 2 Survival rate (free from any cause of death).

of procedure-related events was comparable between the two groups. There were no significant differences in nonprocedure-related events needing surgical repair for access sites, renal dysfunction with or without continuous renal replacement therapy, overall stroke, and bleeding either needing or not needing transfusion between the two groups. Significantly, no patient had paraplegia in either group. Nearly one third of patients had transient fever in hospital. Moreover, at the end of follow-up (mean 3.13 years in the chronic group and 2.76 years in the acute

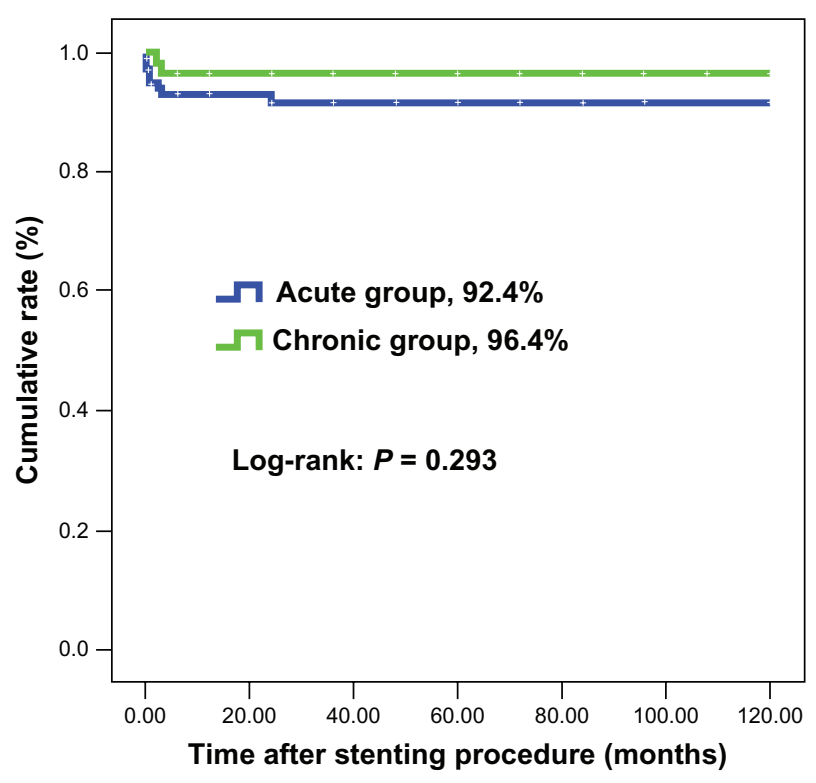

Figure 3 Survival rate (free from aorta-related death). group, $P=0.478$ ), overall and aorta-related mortality rates were $11.0 \%$ and $7.6 \%$, respectively, in the acute group, and not significantly different from those in the chronic group (3.6\% and 3.6\%, $P=0.148$ and $P=0.506$, respectively, Figures 2 and 3). Both the false and true lumen showed significant remodeling over time, with $>93 \%$ complete false-lumen thrombosis and evidence of aortic remodeling within 6 months of the index procedure.

By propensity score matching, 51 pairs of patients were matched. There were no statistically significant differences in procedure-related events, nonprocedure-related events, or any other study endpoints between the two groups (Table 4). By regression analysis, type I endoleak (hazards ratio 0.076, 95\% confidence interval $0.022-0.263, P<0.001$ ) and untreated tear (odds ratio $0.103,95 \%$ confidence interval $0.020-0.176, P<0.001)$ were independent risk factors for procedure-related events and death during follow-up before and after matching.

\section{Discussion}

The major findings of the current study are as follows. Patients in the acute group had a significantly increased rate of procedure-related events when compared with those in the chronic group, although this difference became smaller after propensity score matching; the chronic false lumen was progressively enlarged despite maximal medical therapy; and the presence of type I endoleak and untreated tears predicted death.

\section{Aorta remodeling over time}

Persistent enlargement of the false lumen was seen in $50 \%$ of patients in this study. Implantation of a stent graft was associated with significant shrinkage of the false lumen. Although remodeling over the whole aortic artery was not heterogeneous, ${ }^{8}$ our results show that shrinkage of the false lumen was positively correlated with the increase in the true lumen, with no significant difference between the chronic and acute groups. However, reduction in the diameter of the false lumen in the chronic group was greater when compared with that in the acute group. This is not surprising, because patients in the chronic group had a larger false lumen at baseline. Importantly, similar to previous studies, ${ }^{8,17,18}$ our results confirmed $>93 \%$ complete false-lumen thrombosis. As a result, stent graft provides a strong enough scaffolding for the dissected aorta and puts patients in a stable status via significant aorta remodeling and complete thrombosis of the false lumen. 
Table 4 Comparison of worse events between chronic vs acute groups after propensity score matching

\begin{tabular}{|c|c|c|c|}
\hline & Chronic $(n=5 I)$ & Acute $(n=5 I)$ & $P$ \\
\hline In-hospital overall events, $\mathrm{n}(\%)$ & $6(11.5)$ & $10(19.6)$ & 0.289 \\
\hline Overall death & 0 & $3(5.9)$ & 0.118 \\
\hline Procedure-related events, $\mathrm{n}(\%)$ & $3(5.9)$ & $5(9.8)$ & 0.488 \\
\hline Reverse dissection & $I(2.0)$ & 0 & 1.000 \\
\hline Malperfusion & $2(3.9)$ & $2(3.9)$ & 1.000 \\
\hline Dissection rupture & 0 & I $(2.0)$ & 0.495 \\
\hline Type I leakage & $I(2.0)$ & $5(9.8)$ & 0.112 \\
\hline LSCA occlusion leading stroke & 0 & I $(2.0)$ & 0.495 \\
\hline Non-procedure-related events, $\mathrm{n}(\%)$ & $3(5.9)$ & $6(11.8)$ & 0.319 \\
\hline Acutemyocardial infarction & 0 & 0 & NS \\
\hline Cancer & 0 & 0 & NS \\
\hline Multi-organ failure & 0 & I (2.0) & 0.495 \\
\hline Non-LSCA occlusion leading stroke & $3(5.9)$ & $4(7.8)$ & 0.715 \\
\hline Surgical operation for access site, $\mathrm{n}(\%)$ & I $(2.0)$ & 0 & 1.000 \\
\hline Transient renal failure, $\mathrm{n}(\%)$ & $4(7.8)$ & $7(13.7)$ & 0.358 \\
\hline Without needing dialysis & $3(5.9)$ & $6(11.8)$ & 0.319 \\
\hline Needing CRRT & $\mathrm{I}(2.0)$ & $\mathrm{I}(\mathrm{I} .8)$ & 1.000 \\
\hline Reversable central complications, n (\%) & $I(2.0)$ & $10(8.5)$ & 0.107 \\
\hline Overall stroke, n (\%) & $3(5.9)$ & $5(9.8)$ & 0.488 \\
\hline Paraplegia, $n(\%)$ & 0 & 0 & NS \\
\hline Deep venous thrombus, $\mathrm{n}(\%)$ & $\mathrm{I}(2.0)$ & 0 & 0.322 \\
\hline Bleeding, n (\%) & $2(3.9)$ & $2(3.9)$ & 1.000 \\
\hline Needing transfusion & $\mathrm{I}(2.0)$ & $\mathrm{I}(1.9)$ & 1.000 \\
\hline Death at the end of follow-up, $n$ (\%) & $2(3.9)$ & $3(5.9)$ & 0.678 \\
\hline Aortic-related death & $2(3.9)$ & I (2.0) & 1.000 \\
\hline
\end{tabular}

Abbreviations: LSCA, left subclavian artery; CRRT, continuous renal replacement therapy.

\section{Clinical outcomes in acute versus chronic patients}

Most studies analyzing clinical events overall in patients with type $\mathrm{B}$ dissection ${ }^{19-21}$ have reported lower event rates after endovascular repair than after surgical reconstruction in chronic patients. In their study of a small patient sample $(\mathrm{n}=38)$, Kato et $\mathrm{a}{ }^{10}$ reported early and late complication rates of $33 \%$ and $36 \%$ in acute (<one month) patients compared with $4 \%$ and $0 \%$ in chronic ( $\geq$ one month) patients. However, Kato et al did not report the actual number of patients having a time interval $<2$ weeks from symptom onset. In terms of acute patients ( $<2$ weeks), Dake et al were the first to report on endovascular stent grafting for treatment of acute aortic dissection in the clinical setting. ${ }^{22}$ They treated 19 patients with acute dissection, and the mortality rate in their series was $21 \%$.

Based on our data, the procedure-related event rate in acute patients was significantly higher than that in the chronic group $(P=0.021)$, and was mainly driven by organ or peripheral artery malperfusion ( $11.0 \%$ versus $3.6 \%$ ) and type I endoleak $(11.9 \%$ versus $1.8 \%)$, similar to our previous study. ${ }^{23}$ The process of aneurysmal degeneration at the portion proximal to the stent in the acute stage has not been clearly elucidated so far. The present data indicate that persistent enlargement of the false lumen occurred in $50 \%$ of patients who survived the acute phase. Therefore, selection of the landing zone and complete coverage of tears were two critical issues in order to avoid endoleak, ${ }^{10,23}$ so the stent should be landed at least 3-5 mm proximal to the tear. Furthermore, distortion of the stent system was somewhat inevitable if the descending aorta was extremely tortuous. As a result, a more flexible and dedicated stent system is needed.

Designing a randomized study comparing stent grafting for acute versus chronic type B dissection is impossible in the clinical setting. Because of the presence of differences in baseline characteristics between acute and chronic patients, direct comparison of clinical outcomes of endovascular repair for acute versus chronic dissection is not feasible. Thus, propensity score matching is a useful tool for use in a nonrandomized study in order to minimize selection bias. ${ }^{24,25} \mathrm{After}$ propensity score matching, the difference in the procedure-related complication rate between the two groups became smaller, even though type I endoleak still tended to be high in the acute group. However, regression analysis before and after propensity score matching consistently showed that type I endoleak and untreated tears were predictors of procedure-related complications and mortality. Again, this underscores the importance of avoiding endoleak. 


\section{Untreated tears}

Multiple tears have been reported in some patients from previous studies, ${ }^{1-23}$ but actual rates are not known. From the current study, one quarter of the patients in the acute group had second tears, and complete repair was achieved in only one patient. Because all second tears localized at a level close to the orifice of the renal artery, a site where there are several major arteries taking off, endovascular repair for these additional tears was difficult and dangerous. This is one of the possible explanations for why patients in the acute group had a high incidence of organ or peripheral artery malperfusion. Taking these into consideration, extension of the landing zone to minimize type I endoleak and complete endovascular repairs for all tears is important.

\section{Limitations}

Obviously, classification of patients as chronic or acute was not random, leading to the relative small patient sample in the chronic group. Another limitation was that all patients having type B dissection were not studied systematically, with more stable chronic patients being put on long-term medication. We did not analyze the difference in clinical outcomes between surgical and percutaneous treatment because of the small number of patients in the surgical group. Selection of stent diameter was based on different criteria for chronic and acute patients. This bias could not be excluded when relatively more type I endoleak in acute group was considered, although the stent diameter in the acute group was comparable with that in the chronic group. Finally, the small sample size could be another reason why there was no significant difference in outcome after propensity score matching between the two groups. In conclusion, we found that endovascular repair for acute or chronic type B dissection was safe and feasible, resulting in comparable long-term clinical results between the two groups after propensity score matching.

\section{Acknowledgments}

We thank Ms Ling Lin, Ms Yin-Yin Zhao, and Ms Hai-Mei $\mathrm{Xu}$ for their contribution to data collection and remote monitoring. Importantly, we acknowledge Professor Bao-Xian Duan for independent analysis of the clinical events.

\section{Disclosure}

We appreciate the grant support provided by the Nanjing Health Bureau (NJG/HF 199901200) for this research.

\section{References}

1. Hagan PG, Nienaber CA, Isselbacher EM, et al. The International Registry of Acute Aortic Dissection (IRAD). JAMA. 2000;283: 897-903.

2. Mukherjee D, Eagle KA. Aortic dissection - an update. Curr Probl Cardiol. 2005;30:287-325.

3. Tsai TT, Fattori R, Trimarchi S, et al. Long-term survival in patients presenting with type B acute aortic dissection: insights from the International Registry of Acute Aortic Dissection. Circulation. 2006; 114:2226-2231.

4. Glower DD, Speier RH, White WD, et al. Management and long-term outcome of aortic dissection. Ann Surg. 1991;214:31-41.

5. Lansman SL, McCullough JN, Nguyen KH, et al. Subtypes of acute aortic dissection. Ann Thorac Surg. 1999;67:1975-1978.

6. Shimono T, Kato N, Tokui T, et al. Endovascular stent-graft repair for acute type A aortic dissection with an intimal tear in the descending aorta. J Thorac Cardiovasc Surg. 1998;116:171-173.

7. Fann JI, Miller DC. Aortic dissection. Ann Vasc Surg. 1995;9:311-323.

8. Nienaber CA, Kische S, Akin I, et al. Strategies for subacute/chronic type B aortic dissection: The Investigation of Stent Grafts in Patients with Type B Aortic Dissection (INSTEAD) trial 1-year outcome. J Thorac Cardiovasc Surg. 2010;140:S101-S108.

9. Nienaber CA, Kische S, Ince H. Thoracic aortic stent-graft devices: problems, failure modes and applicability. Semin Vasc Surg. 2007;20: 81-89.

10. Kato N, Shimono T, Hirano T, et al. Midterm results of stent-graft repair of acute and chronic aortic dissection with descending tear: the complicationspecific approach. Thorac Cardiovasc Surg. 2002;124:306-312.

11. Onitsuka S, Akashi H, Tayama K, et al. Long-term outcome and prognostic predictors of medically treated acute type B aortic dissections. Ann Thorac Surg. 2004;78:1268-1273.

12. Nienaber CA, Kische S, Rehders TC, et al. Rapid pacing for better placing: a comparison of techniques for precise deployment of endograft in the thoracic aorta. $J$ Endovasc Ther. 2007;14:506-512.

13. vn Knobelsdorff G, Höppner RM, Tonner PH, et al. Induced arterial hypotension for interventional thoracic aortic stent-graft placement: impact on intracranial haemodynamics and cognitive function. Eur $J$ Anaesthesiol. 2003;20:134-140.

14. Rehders TC, Petzsch M, Ince H, et al. Intentional occlusion of the left subclavian artery during stent-graft implantation in the thoracic aorta: risk and relevance. $J$ Endovasc Ther. 2004;11:659-666.

15. Chaikof EL, Blankensteijn JD, Harris PL, et al; Ad Hoc Committee for Standardized Reporting Practices in Vascular Surgery of The Society for Vascular Surgery/American Association for Vascular Surgery. J Vasc Surg. 2002;35:1048-1060.

16. Bolland K, Whitehead J. Formal approaches to safety monitoring of clinical trials in life-threatening conditions. Stat Med. 2000;19: 2899-2917.

17. Rodriguez JA, Olsen DM, Lucas L, et al. Aortic remodeling after endografting of thoracoabdominal aortic dissection. J Vasc Surg. 2008;47:1188-1194.

18. Schoder M, Czerny M, Cejna M, et al. Endovascular repair of acute type B aortic dissection: long-term follow-up of true and false lumen diameter changes. Ann Thorac Surg. 2007;83:1059-1066.

19. Nienaber CA, Fattori R, Lund G, et al. Nonsurgical reconstruction of thoracic aortic dissection by stent-graft placement. $N$ Engl J Med. 1999;340:1539-1545.

20. Inoue $\mathrm{K}$, Hosokawa $\mathrm{H}$, Iwase $\mathrm{T}$, et al. Aortic arch reconstruction by transluminally placed endovascular branched stent graft. Circulation. 1999;100 Suppl:II316-II321.

21. Kato N, Hirano T, Takatsugu S, et al. Treatment of chronic type B aortic dissection with endovascular stent-graft placement. Cardiovasc Intervent Radiol. 2000;23:60-62.

22. Dake MD, Kato N, Mitchell RS, et al. Endovascular stent-graft placement for the treatment of acute aortic dissection. $N$ Engl J Med. 1999;340:1546-1552. 
23. Chen S, Yei F, Zhou L, et al. Endovascular stent-grafts treatment in acute aortic dissection (type B): clinical outcomes during early, late, or chronic phases. Catheter Cardiovasc Interv. 2006;68:319-325.

24. D'Agostino RB Jr. Propensity score methods for bias reduction in the comparison of a treatment to a non-randomized control group. Stat Med. 1998;17:2265-2281.
25. D'Agostino RB Jr. Propensity scores in cardiovascular research. Circulation. 2007;115:2340-2343.

\section{Publish your work in this journal}

Patient Preference and Adherence is an international, peer-reviewed, open access journal focusing on the growing importance of patient preference and adherence throughout the therapeutic continuum. Patien satisfaction, acceptability, quality of life, compliance, persistence and their role in developing new therapeutic modalities and compounds to optimize clinical outcomes for existing disease states are major areas of interest. This journal has been accepted for indexing on PubMed Central. The manuscript management system is completely online and includes a very quick and fair peer-review system. Visit http://www.dovepress.com/ testimonials.php to read real quotes from published authors.

Submit your manuscript here: http://www.dovepress.com/patient-preference-and-adherence-journal 